\title{
Assessment of sexual dysfunction and associated factors among patients with schizophrenia in Ethiopia, 2017
}

\author{
Tolesa Fanta ${ }^{1 *}$ D, Kibrom Haile ${ }^{1}$, Dessie Abebaw ${ }^{1}$, Dawit Assefa ${ }^{2}$ and Getahun Hibdye ${ }^{3}$
}

\begin{abstract}
Background: Sexual dysfunction is remarkably prevalent amongst psychiatric patients than general population. This might be due to either the nature of the illness itself or the unwanted effect of the medication they are taking for the illness which limits the capability of forming interpersonal and sexual relationships. This issue is rarely raised in developing countries, and the aim of this study was to assess magnitude and factors contributing to sexual dysfunction among patients with Schizophrenia.
\end{abstract}

Method: Hospital based cross sectional study was conducted at Amanuel Mental Specialized Hospital from January to June 2017. The sample required for this study was determined by using single population proportion formula and the final sample size was 423; and systematic random sampling was used to select participants. We used Change in Sexual Functioning Questionnaire to measure sexual dysfunction. The collected data was cleaned, interred in to Epi data and transferred to SPSS version 20 for farther analysis. The OR with $95 \% \mathrm{Cl}$ was used to measure association and $P$-value $<0.05$ was used as statistically significant.

Result: A total of 422 patients with Schizophrenia were involved in the study. The prevalence of General Sexual dysfunction was 82.7\%; and in male and female patients the prevalence was 84.5 and $78.6 \%$ respectively. Marital status (Unmarried, Divorced and widowed, history of relapse and poor quality of life were associated significantly to global sexual dysfunction.

Conclusion: The magnitude of Sexual dysfunction was found to be high among patients with schizophrenia and it is associated with different factors like unmarried, divorced, widowed, relapse and poor quality of life. Treating physicians should be conscious to sexual dysfunction during evaluation and treatment of patients with Schizophrenia. Special attention should be given to single, divorced, widowed patients and patients with history of relapse to improve quality of life of this patients.

Keywords: Sexual dysfunction, Schizophrenia, Amanuel hospital

\section{Background}

Sexual life is a natural and complex component of human behaviors that is determined by many physiological and psychological factors. Sexual dysfunction is a public health issue which affects an estimate of $43 \%$ women and $31 \%$ men in US [1]. The commonest dysfunction among women is sexual desire dysfunction complained by around $30 \%$ of women. The commonest dysfunctions

\footnotetext{
* Correspondence: tole.fanta@gmail.com

${ }^{1}$ Amanuel Mental Specialized Hospital Research and Training Department,

Addis Ababa, Ethiopia

Full list of author information is available at the end of the article
}

among men are erectile dysfunction and premature ejaculation. Any problem in main area of sexual behavior; interest, arousal, orgasm/ejaculation and like can arise as the result of either pathophysiological or psychological mechanisms [2].

Sexual dysfunction is extremely prevailing in psychiatric patients than general population. This is related to either the nature of the illness itself (negative symptoms like avolition, anhedonia and blunted affect) or the unwanted effect of the medication they are taking for the illness (effect on prolactin secretion and obesity) which

(C) The Author(s). 2018 Open Access This article is distributed under the terms of the Creative Commons Attribution 4.0 International License (http://creativecommons.org/licenses/by/4.0/), which permits unrestricted use, distribution, and 
limits the capability of forming interpersonal and sexual relationships [1].

The peak age of onset of schizophrenia in both sexes is during the reproductive period. Consequently impaired sexual functioning among persons with schizophrenia can affect their ability to have a family, and, thus, to fulfill traditional social expectations [3]. The role of antipsychotic drugs in sexual functioning of people with schizophrenia is becoming a recent concern of researchers since this side-effect may decrease adherence to treatment, especially among males, because they are more concerned about sexual functioning than females) [4].

Sexual dysfunction has many impacts on patients with Schizophrenia. It has direct or indirect association with quality of life, adherence, difficulty to form and maintain family, and lastly may develop depression and suicidality $[3,5,6]$.

Despite the importance and high prevalence of the problem, this patients do not inform the problem either due to feeling of discomfiture or for the reason that they do not view it as a treatable problem [6]. In other hand psychiatrists and other specialists significantly undervalue or even neglect the existence of the problem probably due to embarrassment of talking about sexual problems with patients, lack of time and viewing difficulties in this area as minor compared to psychotic symptoms. In spite of these realities there are limited or no researches conducted in this country regarding sexual dysfunction and its influence on patients with Schizophrenia. Therefore, this study aims to evaluate the prevalence of sexual dysfunction among patients with schizophrenia and see if there is any association between socio-demographic factors, different clinical factors like medication related factors, co-morbid physical or psychiatric conditions, and substance use and sexual dysfunction among patients with Schizophrenia.

\section{Methods}

\section{Study design and study period}

Institutional based cross sectional study was conducted from January to June 2017.

\section{Study area}

The study was conducted at Amanuel Mental Specialized Hospital (ASMH) located in the country's capital, Addis Ababa. Amanuel mental specialized hospital is the only mental specialized hospital where patients mainly afflicted with severe mental illness, including schizophrenia, are treated. The hospital gives service for patients from all over the country. It has a case load of more than 10,000 patients per month and schizophrenia is the number one diagnosis, diagnosed in more than $60 \%$ of the patients visiting the hospital.

\section{Population}

All patients with Schizophrenia who are on follow up at AMSH are the source populations and people with Schizophrenia in the age group $18 \&$ above who were on treatment at AMSH during the study period were study population.

\section{Eligibility criteria}

All patients with Schizophrenia in age group 18 and above were included in the study and the patients in exacerbation phase were excluded from the study.

\section{Sample size}

The minimum number of sample required for this study wasdetermined by using single population proportion formula and the final sample size for this study with $10 \%$ nonresponse rate was 423 .

\section{Sampling procedure}

Systematic random sampling technique with interval of 11 was used to select the participants from 4885 patients with schizophrenia came for follow up during data collection period.

\section{Study variables}

The outcome variable for this study was Sexual Dysfunction. Socio-demographic factors, duration of the illness, duration on treatment, medication, dosage and frequency, comorbid known chronic medical illness, history of admission and relapse, adherence to drug, Quality of life, Suicide, Depression and history of substance use were explanatory variables for this study.

\section{Instruments}

The gold standard instrument which is Structured Clinical Interview for DSM- IV-TR axis I disorders (SCID) was used to confirm a diagnosis of Schizophrenia. Sexual dysfunction was measured by using Changes in Sexual Functioning Questionnaires (CSFQ-14). It has separate forms for female (CSFQ -F-C) and for Male (CSFQ-M-C) Clinical Version. It contains14 items and is used to assess the presence/absence of sexual dysfunction in study participants. All the 14 items should be answered on a five Likert scale to assess global sexual dysfunction. The score $<=47$ for male and $<=41$ for female indicates the presence of global sexual dysfunction. The tool can also measure the sexual dysfunction components: Pleasure (Item 1), Desire/frequency (Item 2 and 3), Desire/interest (Item 4, 5 and 6), Arousal/erection (Item 7, 8 and 9) and Orgasm/ejaculation (Item 11, 12 and 13) It has Cronbach's $\alpha$ of 0.91 and 0.93 for male and female scales, respectively [7, 8]. WHOQOL-BREF was used to measure quality of life. This instrument is cross culturally validated and currently in use in 


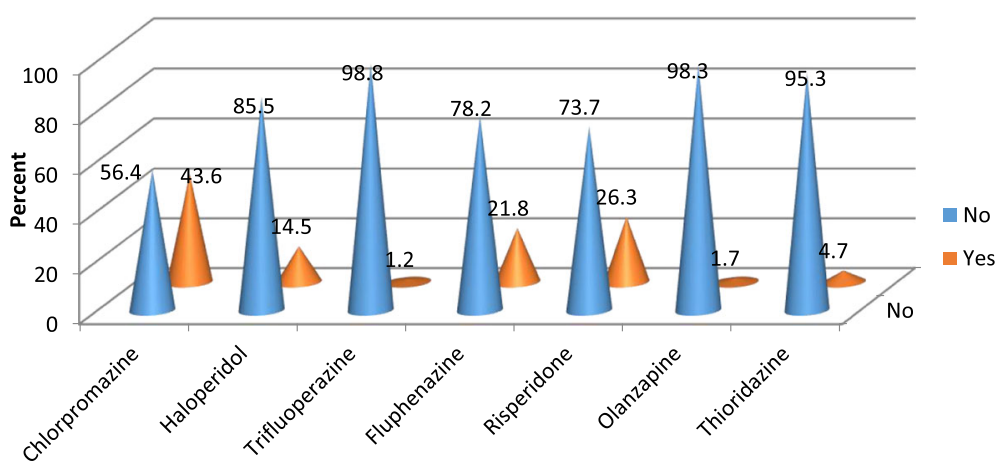

Fig. 1 Antipsychotic Medications prescribed for the participants

different languages [9]. PHQ-9 was used to measure depression in patients with schizophrenia. This instrument has sensitivity of $86 \%$ and specificity of $67 \%$ in diagnosing depression [10]. Eight -item Morisky medication adherence Scale was used to measure medication adherence. It is valid and reliable with Cronbach's $\alpha$ of $83 \%$; and, sensitivity and specificity of 93 and 53\% respectively [11]. The English version of the instruments was translated to local language and back retranslated to English by language professionals and psychiatrists.

\section{Data quality control}

17 masters level mental health students were hired for data collection and two masters level mental health professionals were hired to supervise the data collectors. The data collectors were given a two days training on questionnaire and way of assessment. Pre-test was conducted 15 days before the start of actual data collection to know the time needed to complete one questionnaire and to know whether the questionnaire used is understandable to the study participants or not. The data collected during the pre-test was not included in the final analysis.

\section{Data processing and analysis}

Data was coded and entered to Epi data and transferred to Statistical Package for Social Sciences version 20 (SPSS-20) for further analysis. Descriptive statistical analysis was used to estimate the frequencies and percentages of the variables. Bivariate and multivariate logistic regression analysis was used to see the association between outcome and explanatory variables. The strength of the association was measured by odds ratio with $95 \%$ $\mathrm{CI}$ and $P$-value less than 0.05 was considered as statistically significant.

\section{Ethical consideration}

Ethical clearance was obtained from Amanuel Mental Specialized Hospital Ethical Review Committee. The Four Item Abbreviated Mental Test (AMT4) was used to measure the capacity of the patient to give consent. Then the purpose, importance and confidentiality of the information gathered was explained to each of the competent participant before the start of interview. Participants were also informed that they will never get any benefit because of participation in the study and no harm on them if they would not agree to participate or withdraw from participation during the data collection

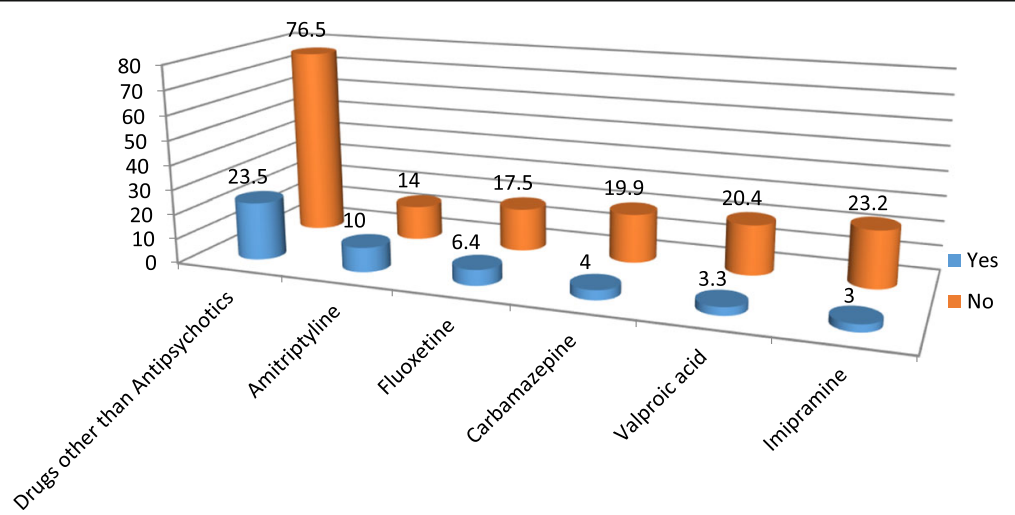

Fig. 2 Medications prescribed for comorbid psychiatric problems 
Table 1 Distribution of participants by socio-demographic factors and clinical factors

\begin{tabular}{|c|c|c|c|c|}
\hline No. & Variables & Variables category & Frequency (422) & Percentage (100\%) \\
\hline \multirow[t]{4}{*}{1} & \multirow[t]{4}{*}{ Age } & $18-24$ & 35 & 8.3 \\
\hline & & $25-34$ & 174 & 41.2 \\
\hline & & $35-44$ & 150 & 35.5 \\
\hline & & $>=45$ & 63 & 14.9 \\
\hline \multirow[t]{2}{*}{2} & \multirow[t]{2}{*}{ Sex } & Female & 132 & 31.3 \\
\hline & & Male & 290 & 68.7 \\
\hline \multirow[t]{3}{*}{3} & \multirow[t]{3}{*}{ Marital Status } & Married & 154 & 36.5 \\
\hline & & Single & 224 & 53.1 \\
\hline & & Divorced and Widowed & 44 & 10.4 \\
\hline \multirow[t]{4}{*}{4} & \multirow[t]{4}{*}{ Ethnicity } & Oromo & 140 & 33.2 \\
\hline & & Amhara & 126 & 29.9 \\
\hline & & Gurage & 98 & 23.2 \\
\hline & & Others* & 58 & 13.7 \\
\hline \multirow[t]{3}{*}{5} & \multirow[t]{3}{*}{ Religion } & Orthodox & 228 & 54 \\
\hline & & Protestant & 79 & 18.7 \\
\hline & & Muslim & 115 & 27.3 \\
\hline \multirow[t]{5}{*}{6} & \multirow[t]{5}{*}{ Educational Status } & No formal education & 31 & 7.3 \\
\hline & & Primary school & 137 & 32.5 \\
\hline & & High School & 164 & 38.9 \\
\hline & & Diploma & 46 & 10.9 \\
\hline & & Degree and above & 44 & 10.4 \\
\hline \multirow[t]{4}{*}{7} & \multirow[t]{4}{*}{ Occupation } & Private & 135 & 32 \\
\hline & & Governmental & 42 & 11.1 \\
\hline & & Unemployed & 142 & 33.6 \\
\hline & & Others(House wife, Daily labourers) & 98 & 23.2 \\
\hline \multirow[t]{2}{*}{8} & \multirow[t]{2}{*}{ Residence } & Urban & 353 & 83.6 \\
\hline & & Rural & 69 & 16.4 \\
\hline \multirow[t]{2}{*}{9} & \multirow[t]{2}{*}{ Frequency of Chlorpromazine per day } & Once/day & 149 & 81.0 \\
\hline & & $>=2$ & 35 & 19 \\
\hline \multirow[t]{2}{*}{10} & \multirow[t]{2}{*}{ Frequency of Haloperidol per day } & Once/day & 46 & 75.4 \\
\hline & & $>=2$ & 15 & 24.6 \\
\hline \multirow[t]{2}{*}{11} & \multirow[t]{2}{*}{ Frequency of Trifluoperazine per day } & Once/day & 3 & 60 \\
\hline & & $>=2 /$ day & 2 & 40 \\
\hline \multirow[t]{2}{*}{12} & \multirow[t]{2}{*}{ Frequency of Fluphenazineper day } & Once/month & 91 & 98.9 \\
\hline & & $>=2 /$ month & 1 & 1.1 \\
\hline 13 & Frequency of Resperidone per day & Once/day & 71 & 64.5 \\
\hline & & $>=2 /$ day & 39 & 35.5 \\
\hline 14 & Frequency of Olanzapine per day & Once/day & 5 & 62.5 \\
\hline & & $>=2 /$ day & 2 & 37.5 \\
\hline 15 & Frequency of Thioridazine per day & Once/day & 20 & 100 \\
\hline & & $>=2 /$ day & 0 & 0 \\
\hline 16 & Duration of the illness & $<=5$ years & 174 & 41.2 \\
\hline & & $6-10$ years & 119 & 28.2 \\
\hline & & $>=11$ years & 129 & 30.6 \\
\hline
\end{tabular}


Table 1 Distribution of participants by socio-demographic factors and clinical factors (Continued)

\begin{tabular}{|c|c|c|c|c|}
\hline No. & Variables & Variables category & Frequency (422) & Percentage (100\%) \\
\hline \multirow[t]{3}{*}{17} & \multirow[t]{3}{*}{ Duration on treatment } & $<=5$ years & 207 & 49.1 \\
\hline & & $6-10$ years & 103 & 24.4 \\
\hline & & $>=11$ years & 112 & 26.5 \\
\hline \multirow[t]{2}{*}{18} & \multirow[t]{2}{*}{ Admission } & No & 254 & 60.2 \\
\hline & & Yes & 168 & 39.8 \\
\hline \multirow[t]{2}{*}{19} & \multirow[t]{2}{*}{ Number of admission } & $<=1$ & 96 & 57.1 \\
\hline & & $>=2$ & 72 & 42.9 \\
\hline \multirow[t]{2}{*}{20} & \multirow[t]{2}{*}{ Relapse } & No & 226 & 53.6 \\
\hline & & Yes & 196 & 46.4 \\
\hline \multirow[t]{2}{*}{21} & \multirow[t]{2}{*}{ Number of relapse } & $<=1$ & 96 & 49 \\
\hline & & $>=2$ & 100 & 51 \\
\hline \multirow[t]{2}{*}{22} & \multirow[t]{2}{*}{ Depression } & No & 346 & 82 \\
\hline & & Yes & 76 & 18 \\
\hline \multirow[t]{2}{*}{23} & \multirow[t]{2}{*}{ Non-Adherence } & No & 203 & 48.1 \\
\hline & & Yes & 219 & 51.9 \\
\hline \multirow[t]{3}{*}{24} & \multirow[t]{3}{*}{ Poor Quality of life } & No & 217 & 51.4 \\
\hline & & Yes & 205 & 48.6 \\
\hline & & Yes & 0 & 0 \\
\hline \multirow[t]{2}{*}{25} & \multirow[t]{2}{*}{ Suicidal Ideation } & No & 373 & 88.4 \\
\hline & & Yes & 49 & 11.6 \\
\hline \multirow[t]{2}{*}{26} & \multirow[t]{2}{*}{ Suicidal Attempt } & No & 406 & 96.2 \\
\hline & & Yes & 16 & 3.8 \\
\hline
\end{tabular}

process. Finally, their willingness to be involved in the study was asked and written consent was obtained.

At the time of data collection the investigator, supervisor and data collectors followed 'code of ethics' and obeyed the rules \& regulations of the hospital. Participant's privacy was kept strictly at the time of data collection.

\section{Result}

A total of 422 patients with schizophrenia participated on the study with response rate of $99.76 \%$. Among the participants $290(68.7 \%)$ were male and 132(31.3\%) were female in gender. The mean age of the participants is 35.46 with \pm 9.25 standard deviation. Majority of the participants 353(83.6\%) were from urban area. The most frequently prescribed antipsychotic drug is chlorpromazine 184(43.6\%) followed by Resperidone 111 (26.3\%) (Fig. 1). Amitriptyline is the most frequently prescribed drug among the medications ordered for other comorbid psychiatric conditions 42(41.6\%) followed by Fluoxetine 27(26.7\%) (Fig. 2). Most of the participants take their medications once in twenty four hours (Table 1). Among

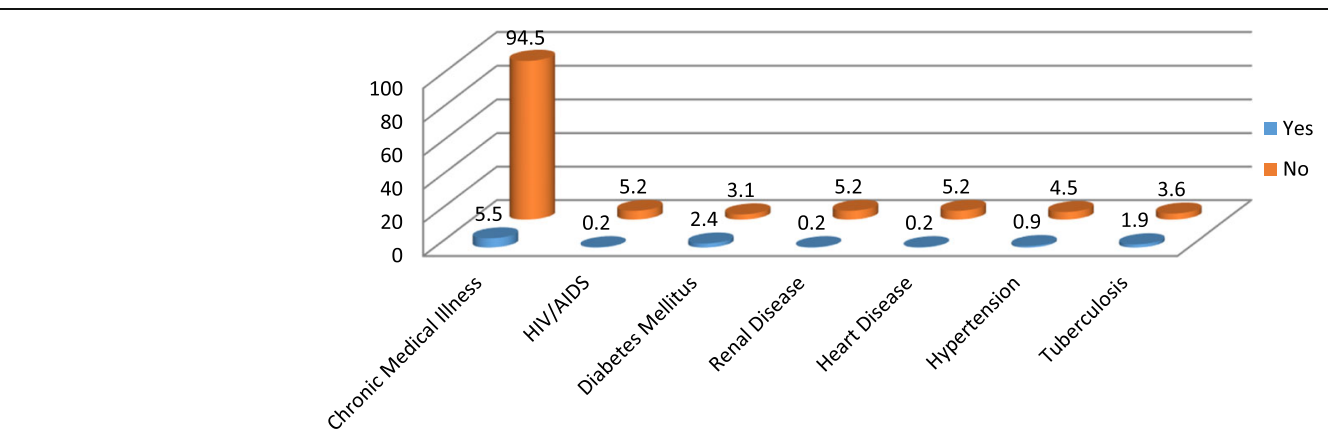

Fig. 3 Magnitude of Chronic Medical IIIness among Patients with Schizophrenia 


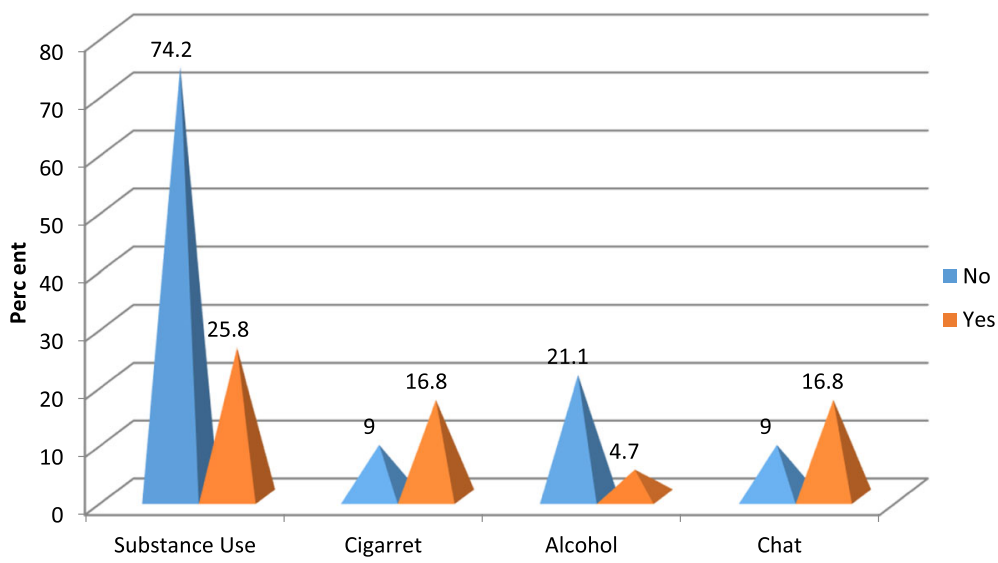

Fig. 4 Magnitude of Substance Use among Patients with Schizophrenia

the study participants, 23(5.5\%) were found to have at least one comorbid other medical illness. The most frequently occurring chronic medical illness in patients with Schizophrenia is Diabetes Mellitus 10(2.4\%) followed by Tuber Closes (TB) 8(1.9\%) (Fig. 3). Among the substance users $71(16.8 \%)$ use cigarette and khat users were $71(16.8 \%)$ (Khat and Cigarette are equally consumed) (Fig. 4). The median score of duration of the illness is 7 years with inter quartile range of 6 , and the median score of duration on treatment is 6 years with inter quartile range of 10 . The median score for frequency of admission is 1 with inter quartile range of 1 , and the median score for frequency of relapse is 2 with inter quartile range of 2 . The mean score of Quality of Life of the participants is 60.59 with standard deviation of \pm 9.43 (Table 1 ).

\section{Prevalence of sexual dysfunction among patients with schizophrenia}

The prevalence of General sexual dysfunction among the study participants was $349(82.7 \%)$ with $95 \%$ confidence interval of $(78.9,86.3)$. The overall sexual dysfunction among male participants was 246(84.5\%) with $95 \%$ confidence interval of $(80.3,88.7)$ and it was $103(78.6 \%)$ with $95 \%$ confidence interval of $(71,84.7)$ in female Schizophrenic patients (Fig. 5). Erectile dysfunction $277(95.2 \%)$ is highly prevalent followed by pleasure dysfunction 274(94.2\%) in male participants (Fig. 6). In female participants who had sexual dysfunction the most prevalent sexual dysfunction was pleasure dysfunction 125(94.7\%) followed by arousal/excitement dysfunction 123(93.2\%) (Fig. 7).

\section{Bivariate and multivariate analysis}

After bivariate logistic regression analysis, five variables (Marital status, Resperidone use, Relapse, Depression and Quality of life) met the requirement to proceed to multivariate logistic regression analysis. After multivariate analysis, marital status, history of relapse, and quality of life were found to be significantly associated with global sexual dysfunction. Compared to the married ones, being single, [aOR 4.19, 95\% CI $(2.30,7.64)]$, and being divorced [aOR 2.86,

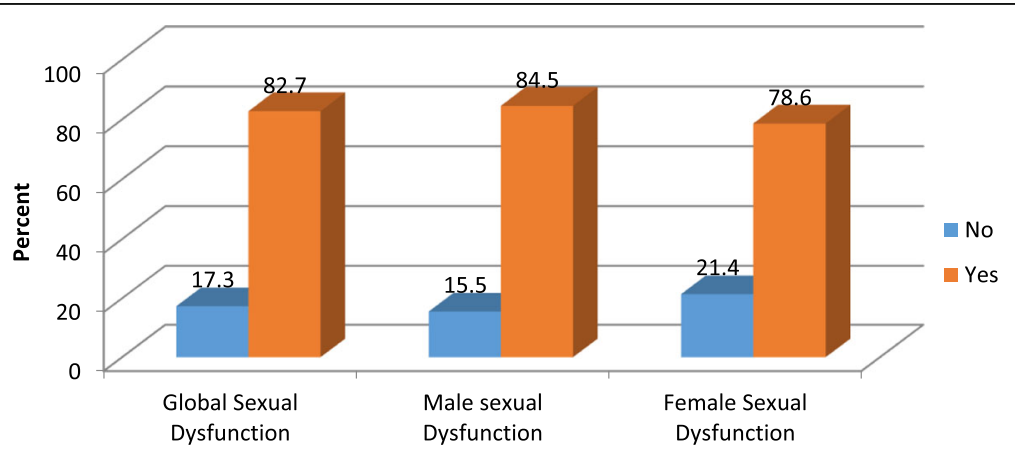

Fig. 5 Global sexual Dysfunction and sexual Dysfunction across Male and Female participants 


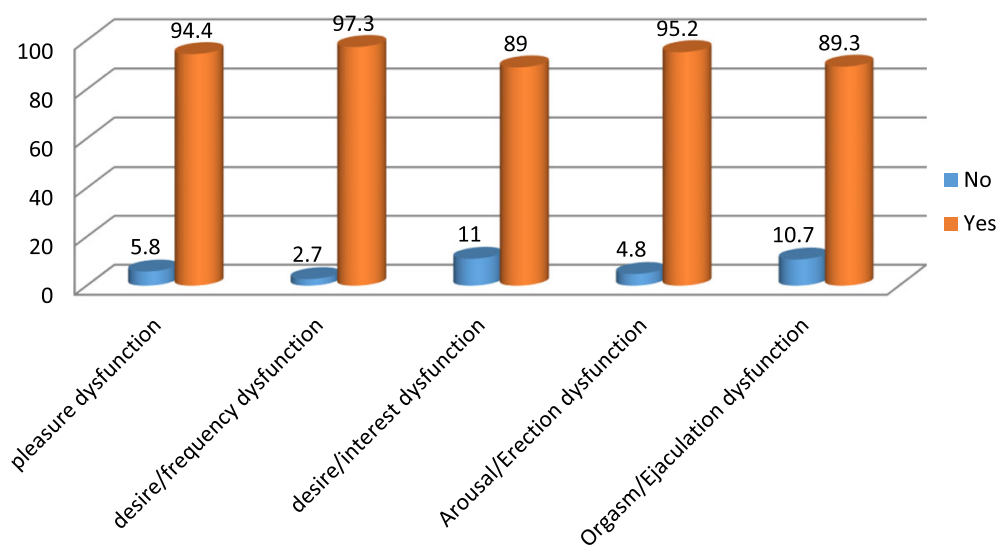

Fig. 6 Components of Sexual Dysfunction among male participants

95\% CI $(1.03,7.90)]$ were significantly associated with General sexual dysfunction. History of relapse, [aOR $2.21,95 \%$ CI $(1.25,3.91)]$, and poor quality of life, [aOR 5.57, 95\% CI $(2.79,11.09)]$ were also significantly associated with General sexual dysfunction at $p$-value $<0.05$ (Table 2).

\section{Discussion}

This study found that magnitude of General sexual dysfunction, and sexual dysfunction across male and female patients with Schizophrenia is extremely high and needs immediate intervention. The prevalence of general sexual dysfunction among patients with Schizophrenia in this study is supported by the comparative study conducted in Egypt on paranoid and non-paranoid schizophrenic patients in which Prevalence of general sexual dysfunction was $80 \%$ in patients with paranoid schizophrenia and $86.7 \%$ in patients with non-paranoid Schizophrenia [7]. The magnitude of general sexual dysfunction in this study is very high when compared to the study conducted in Britain and Iran which was 45 and $31.1 \%$ respectively $[12,13]$. The reason for this significant difference may be explained by socio-cultural difference and difference in measurement instrument to assess sexual dysfunction. In case of the study conducted in Britain, they used Sexual Functioning Questionnaire (SFQ) to assess sexual dysfunction, and the study conducted in Iran used Arizona Sexual Experience Scale (ASEX) $[12,13]$.

Prevalence of sexual dysfunction among male Schizophrenic patients in our study which is $84.5 \%$ in lines with the study conducted by Macdonald in which the magnitude of sexual dysfunction in male Schizophrenic patients is $82 \%$ [14]. Magnitude of sexual dysfunction among female schizophrenic patients in this study which is $78.6 \%$ is lower than that of Macdonald in which prevalence of sexual dysfunction among female schizophrenic patients is $92 \%$, and is higher than that of USA and Turkey in which prevalence of female sexual dysfunction is 59 and $68 \%$ respectively [14-16]. The reason for the discrepancy is probably due to difference in culture and living style which may differ in different countries and population. Difference in measurement tool to assess sexual dysfunction in this particular population is

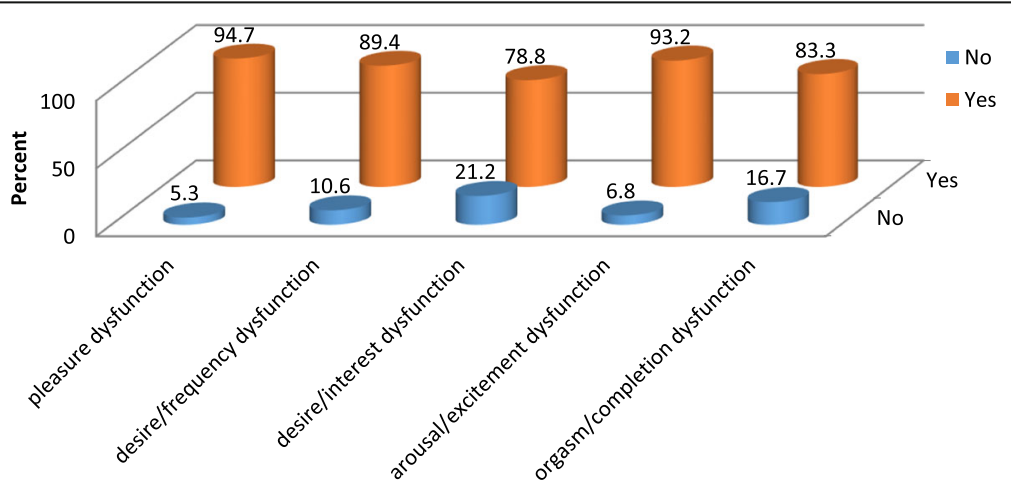

Fig. 7 Components of Sexual Dysfunction among Female Participants 
Table 2 Factors Associated With Sexual Dysfunction Among Patients With Schizophrenia At Amanuel Mental Specialized Hospital/2017

\begin{tabular}{|c|c|c|c|c|c|c|}
\hline \multirow{3}{*}{$\begin{array}{l}\text { Explanatory } \\
\text { variables }\end{array}$} & \multirow{3}{*}{$\begin{array}{l}\text { Variables } \\
\text { category }\end{array}$} & \multicolumn{2}{|c|}{ Sexual Dysfunction } & \multicolumn{2}{|c|}{ Bivariate and Multivariate Analysis } & \multirow[t]{3}{*}{$P$-Value } \\
\hline & & Absent & Present & Bivariate Analysis & Multivariate Analysis & \\
\hline & & & & $\operatorname{COR}(95 \% \mathrm{Cl})$ & $\mathrm{aOR}(95 \% \mathrm{Cl})$ & \\
\hline \multirow[t]{3}{*}{ Marital Status } & Married & 44 & 110 & $1: 00$ & $1: 00$ & \\
\hline & Single & 23 & 201 & $3.49(2.01,6.10)$ & $4.19(2.30,7.64)$ & 0.000 \\
\hline & $\begin{array}{l}\text { Divorced and } \\
\text { Widowed }\end{array}$ & 6 & 38 & $2.53(1.00,6.6 .42)$ & $2.86(1.03,7.90)$ & 0.043 \\
\hline \multirow[t]{2}{*}{ Resperidone } & No & 62 & 249 & 1.00 & 1.00 & \\
\hline & Yes & 11 & 100 & $2.264(1.15,4.48)$ & $1.69(0.82,3.51)$ & \\
\hline \multirow[t]{2}{*}{ Relapse } & No & 30 & 196 & & & \\
\hline & Yes & 43 & 153 & $1.84(1.10,3.06)$ & $2.21(1.25,3.91)$ & 0.007 \\
\hline \multirow[t]{2}{*}{ Depression } & No & 67 & 279 & 1.00 & 1.00 & \\
\hline & Yes & 6 & 70 & $2.80(1.17,6.72)$ & $1.49(0.58,3.83)$ & \\
\hline \multirow[t]{2}{*}{ Quality of life } & Good & 60 & 157 & 1.00 & 1.00 & \\
\hline & Poor & 13 & 192 & $5.64(2.99,10.66)$ & $5.57(2.79,11.09)$ & 0.000 \\
\hline
\end{tabular}

also possible reason for observed difference. In case of USA they used the Global Impression of Sexual Function (GISF) and in Turkey they used Arizona Sexual Experience Scale (ASEX) to assess sexual dysfunction $[15,16]$. Another possible reason for the difference might be criterion used to include the participants in the study. The study conducted in USA included patients who were on conventional antipsychotics and Resperidone where as in our study all schizophrenic patients on any antipsychotic medication were included in the study [16]. Sample size difference across the studies is also possible reason for the discrepancy. Among the factors hypothesized to be contributing factors to sexual dysfunction, unmarried participants were four times more likely to develop sexual dysfunction compared to married participants and Divorced and widowed participants were three times more likely to develop sexual dysfunction compared to married participants. This finding is supported by the study conducted in Nigeria [17]. The possible reason for the association is that the infrequent sexual activity in single and divorced/widowed individuals probably decreases frequency of sexual desire. Having history of relapse exposes two times more to sexual dysfunction compared to the patients without history of relapse. This may be explained by, the more the relapse is frequent the more the illness becomes deteriorated with predomination of negative symptoms of Schizophrenia which potentially affect sexual performance. The need for higher doses of antipsychotics in case of frequent relapse is also another possible reason for this significant association. In this study sexual dysfunction is found to be highly associated with poor quality of life. This result is supported by the study conducted by
Olfson and Kandrakonda S $[18,19]$. This may be due to the fact that an inproper sexual functioning may affect maintaining a satisfying intimate relationship which is the major component of Quality of life.

\section{Conclusion}

Prevalence of Sexual dysfunction is found to be high among patients with Schizophrenia and it needs special attention. The current prevalence of general sexual dysfunction among Schizophrenic patients in our study is high. Regarding sexual dysfunction across sex, male and female sexual dysfunction was also high. Among the hypothesized factors to be risk factors for sexual dysfunction, marital status (single, divorced, widowed), history of relapse and poor quality of life were significantly associated with sexual dysfunction.

\section{Recommendation}

To Amanuel Mental Specialized Hospital.

All Psychiatrists and mental health specialists have to be conscious to sexual dysfunction which is highly prevalent among the patients they are treating, and all patients who are on follow up at this hospital for the case of Schizophrenia should be screened for sexual dysfunction. The overall treatment and care delivered by the hospital should focus on improving quality of life by diagnosing and managing sexual dysfunction properly, rather than focusing only on decreasing the symptom of the illness. Special consideration should be given to a patients with history of relapse, single, widowed and divorced. 


\section{Abbreviations}

AMSH: Amanuel Mental Specialized Hospital; CSFQ: Changes in Sexual Functioning Questionnaires; PHQ-9: Patients Health Questionnaire nine; SD: Sexual Dysfunction; SMI: Severe Mental IIIness; SPSS: Statistical Package of Social Science; USA: United States of America; WHOQOL: World Health Organization Quality of Life

\section{Acknowledgements}

We are grateful to the data collectors and supervisors for their unreserved effort. Our gratitude also goes to Amanuel Mental Specialized Hospital for funding this study. Finally we are grateful to the study participants for their patience.

\section{Funding}

Funding for this study was provided by Amanuel Mental Specialized Hospital.

\section{Availability of data and materials}

The datasets used and/or analysed during the current study are available from thecorresponding author on reasonable request.

\section{Authors' contributions}

TF involved in designing and coordinating overall progress of the study; $\mathrm{KH}$, $D A^{1}, G H$ and $D^{2}$ equally contributed in the design of the study, performed the statistical analyses and critically revised the manuscript. All authors read and approved the final manuscript.

\section{Ethics approval and consent to participate}

Ethical clearance was obtained from Amanuel Mental Specialized Hospital Ethical Review Committee. The Four Item Abbreviated Mental Test (AMT4) was used to measure the capacity of the patient to give consent. Then the purpose, importance and confidentiality of the information gathered was explained to each of the competent participant before the start of interview. Their willingness to participate in the study was asked and written consent was obtained. Participant's privacy was kept strictly at the time of data collection.

\section{Competing interests}

The authors declare that they have no competing interests.

\section{Publisher's Note}

Springer Nature remains neutral with regard to jurisdictional claims in published maps and institutional affiliations.

\begin{abstract}
Author details
'Amanuel Mental Specialized Hospital Research and Training Department, Addis Ababa, Ethiopia. ${ }^{2}$ Amanuel Mental Specialized Hospital, Addis Ababa, Ethiopia. ${ }^{3}$ Amanuel Mental Specialized Hospital Clinical Service Department, Addis Ababa, Ethiopia.
\end{abstract}

Received: 7 September 2017 Accepted: 11 May 2018

Published online: 29 May 2018

\section{References}

1. Zemishlany Z, Weizman A. The impact of mental illness on sexual dysfunction. InSexual Dysfunction 2008 Apr 8 (Vol. 29, pp. 89-106). Karger Publishers.

2. Baggaley M. Sexual dysfunction in schizophrenia: focus on recent evidence. Hum Psychopharmacol Clin Exp. 2008 Apr 1;23(3):201-9.

3. Kelly DL, Conley RR. Sexuality and schizophrenia: a review. Schizophr Bull. 2004 Jan 1;30(4):767-79.

4. Hanssens L, L'Italien G, Loze JY, Marcus RN, Pans M, Kerselaers W. The effect of antipsychotic medication on sexual function and serum prolactin levels in community-treated schizophrenic patients: results from the schizophrenia trial of aripiprazole (STAR) study (NCT00237913). BMC psychiatry. 2008 Dec 22;8(1):1.

5. Kikuchi T, Iwamoto K, Sasada K, Aleksic B, Yoshida K, Ozaki N. Sexual dysfunction and hyperprolactinemia in Japanese schizophrenic patients taking antipsychotics. Prog Neuro-Psychopharmacol Biol Psychiatry. 2012 Apr 27;37(1):26-32.
6. Hashem A.H., Abd El-Gawad T., Ezzat M., Assal A., Goueily T. and El Rakhawy M. A comparative study of sexual function in paranoid versus non-paranoid schizophrenic patients and its relation to serum prolactin Level.Current psychiatry. Vol 13. No. 2. July 2006.

7. Maria Paz Garcia-Portilla, MD, PhD et al. Psychometric properties of the Spanish version of the changes in sexual functioning questionnaire shortform (CSFQ-14) in patients with severe mental disorders. International Society for Sexual Medicine J Sex Med 2011;8:1371-1382..

8. Liu-Seifert H, Kinon BJ, Tennant CJ, Sniadecki J, Volavka J. Sexual dysfunction in patients with schizophrenia treated with conventional antipsychotics or risperidone. Neuropsychiatr Dis Treat. 2009 Apr 8:5:47-54.

9. Oyekanmi AK, Adelufosi AO, Abayomi O, Adebowale TO. Demographic and clinical correlates of sexual dysfunction among Nigerian male outpatients on conventional antipsychotic medications. BMC research notes. 2012 Jun 7:5(1):1.

10. Olfson M, Uttaro T, Carson WH, Tafesse E. Male sexual dysfunction and quality of life in schizophrenia. J Clin psychiatry. 2005 Mar;66(3):331-8.

11. Kandrakonda S, Jally MR, Kesava Reddy SR, Miryala G. Prevalence of sexual dysfunction in patients with mental illness receiving psychotropic medication. AP J Psychol Med. 2014;15(2):235-9.

12. CLAYTON ELMaAH. Reliability and construct validity of the changes in sexual functioning questionnaire short-form (CSFQ-14):. Journal of Sex \& Marital Therapy,. 2006;32:43-52. Departments of Psychiatric Medicine \& Health Evaluation Sciences, University of Virginia, Charlottesville, Virginia, USA.

13. WHO. WHOQOL, user manual, division of mental health and prevention of substance abuse. Geneva, Switzerland.. 1998.

14. Gelaye B, et al. Validity of the patient health Questionnaire-9 for depression screening and diagnosis in East Africa. Psychiatry Res. 2013 December 15: 210(2) https://doi.org/10.1016/.jpsychres.2013.07.015.

15. Morisky E, Ang A, Wood M. Predictive validity of a medication adherence measure in an outpatient setting. J Clin Hypertens (Greenwich). 2008;10: $348-54$.

16. Smith $\mathrm{S}, \mathrm{O}$ 'KEANE VE, Murray R. Sexual dysfunction in patients taking conventional antipsychotic medication. Br J Psychiatry. 2002 Jul 1;181(1):49-55.

17. Ahmadzadeh G, Shahin A. Sexual dysfunctions in the patients hospitalized in psychiatric wards compared to other specialized wards in Isfahan, Iran, in 2012. Advanced biomedical research. 2015;4-225.

18. Macdonald S, Halliday J, MacEwan T, Sharkey V, Farrington S, Wall S, McCreadie RG. Nithsdale schizophrenia surveys 24: sexual dysfunction. Br J Psychiatry. 2003 Jan 2;182(1):50-6.

19. Hocaoglu C, Celik FH, Kandemir G, Guveli H, Bahceci B. Sexual dysfunction in outpatients with schizophrenia in Turkey: a cross-sectional study. Shanghai Arch Psychiatry. 2014 Dec 1;26(6):347-56.

\section{Ready to submit your research? Choose BMC and benefit from:}

- fast, convenient online submission

- thorough peer review by experienced researchers in your field

- rapid publication on acceptance

- support for research data, including large and complex data types

- gold Open Access which fosters wider collaboration and increased citations

- maximum visibility for your research: over $100 \mathrm{M}$ website views per year

At BMC, research is always in progress.

Learn more biomedcentral.com/submissions 